\title{
Volitional Walking via Upper Limb Muscle-Controlled Stimulation of the Lumbar Locomotor Center in Man
}

\author{
Syusaku Sasada, ${ }^{1}$ Kenji Kato, ${ }^{1,2,3}$ Suguru Kadowaki, ${ }^{4}$ Stefan J. Groiss, ${ }^{4,5}$ Yoshikazu Ugawa, ${ }^{4}$ Tomoyoshi Komiyama, ${ }^{6}$ \\ and Yukio Nishimura ${ }^{1,2,7}$ \\ ${ }^{1}$ Department of Developmental Physiology, National Institute for Physiological Sciences, National Institutes of Natural Sciences, Okazaki, 444-8585, Aichi, \\ Japan, ${ }^{2}$ Department of Physiological Sciences, School of Life Science, Graduate University for Advanced Studies, SOKENDAI, Hayama, 240-0193, \\ Kanagawa, Japan, ${ }^{3}$ Japan Society for the Promotion of Science, Chiyoda 102-8472, Tokyo, Japan, ${ }^{4}$ Department of Neurology, School of Medicine, Fukushima \\ Medical University, Fukushima, 960-1295, Japan, ${ }^{5}$ Department of Neurology, Center for Movement Disorders and Neuromodulation \& Institute for Clinical \\ Neuroscience and Medical Psychology, Heinrich-Heine University, Medical Faculty, Düsseldorf, 40233, Germany, ${ }^{6}$ Faculty of Education, Chiba University, \\ Chiba, 263-8522, Japan, and 7Precursory Research for Embryonic Science and Technology, Japan Science and Technology Agency, Chiyoda, 102-0076, \\ Tokyo, Japan
}

Gait disturbance in individuals with spinal cord lesion is attributed to the interruption of descending pathways to the spinal locomotor center, whereas neural circuits below and above the lesion maintain their functional capability. An artificial neural connection (ANC), which bridges supraspinal centers and locomotor networks in the lumbar spinal cord beyond the lesion site, may restore the functional impairment. To achieve an ANC that sends descending voluntary commands to the lumbar locomotor center and bypasses the thoracic spinal cord, upper limb muscle activity was converted to magnetic stimuli delivered noninvasively over the lumbar vertebra. Healthy participants were able to initiate and terminate walking-like behavior and to control the step cycle through an ANC controlled by volitional upper limb muscle activity. The walking-like behavior stopped just after the ANC was disconnected from the participants even when the participant continued to swing arms. Furthermore, additional simultaneous peripheral electrical stimulation to the foot via the ANC enhanced this walking-like behavior. Kinematics of the induced behaviors were identical to those observed in voluntary walking. These results demonstrate that the ANC induces volitionally controlled, walking-like behavior of the legs. This paradigm may be able to compensate for the dysfunction of descending pathways by sending commands to the preserved locomotor center at the lumbar spinal cord and may enable individuals with paraplegia to regain volitionally controlled walking.

Key words: brain-computer interface; locomotion; spinal cord injury; volitional control; walking

\section{Introduction}

Each year, $>130,000$ people worldwide suffer from spinal cord injury (SCI), and many are forced to begin a new, wheelchair bound life (Thuret et al., 2006). An approach to restoring walking ability is functional electrical stimulation (FES), which applies preprogrammed bursts of short electrical pulses to motor nerves or muscles to generate patterned muscle contraction in the paralyzed limb (Peckham et al., 2001; Popovic et al., 2001; Kilgore et al., 2008). This conventional preprogrammed FES, however,

\footnotetext{
Received 0ct. 17, 2013; revised June 23, 2014; accepted June 29, 2014.

Author contributions: S.S., Y.U., T.K., and Y.N. designed research; S.S., K.K., S.K., S.J.G., T.K., and Y.N. performed research; S.S. and K.K. analyzed data; S.S., Y.U., T.K., and Y.N. wrote the paper.

This work was supported by the Precursory Research for Embryonic Science and Technology, Japan Science and Technology Agency (to Y.N.) and the Japan Society for the Promotion of Science (Grant-in-Aid for Scientific Research 23680061 to Y.N., Grant-in-Aid for Scientific Research 24700579 to S.S., and Grant-in-Aid for Scientific Research 25293206 to Y.U.). The funder had no role in study design, data collection and analysis, decision to publish, or preparation of the manuscript. We thank Prof. T. Isa for encouragement and M. Togawa for technical help.

The authors declare no competing financial interests.

Correspondence should be addressed to Dr. Yukio Nishimura, Department of Developmental Physiology, National Institute for Physiological Sciences, National Institutes of Natural Sciences, 0kazaki 444-8585, Aichi, Japan. E-mail: yukio@nips.ac.jp.

DOI:10.1523/JNEUROSCI.4674-13.2014

Copyright $\odot 2014$ the authors $\quad 0270-6474 / 14 / 3411131-12 \$ 15.00 / 0$
}

lacks volitional control because the movements are induced in the preprogrammed manner. In most individuals with SCI, gait disturbance is attributed to a disconnection between rostral brain areas and the lumbar locomotor center, which is still able to induce stepping-like movements (Calancie et al., 1994; Dimitrijevic et al., 1998; Gerasimenko et al., 2008; Harkema et al., 2011). If neural activity above the lesion can be transferred to the locomotor center below the lesion, walking behavior may be induced and controlled volitionally.

It has been shown that spinal circuits can produce functional and rhythmic limb movements without supraspinal input (Forssberg and Grillner, 1973; Grillner and Zangger, 1979). Invasive spinal stimulation can induce locomotor movement in both animals (Saigal et al., 2004; Ichiyama et al., 2005; van den Brand et al., 2012) and humans (Dimitrijevic et al., 1998; Gerasimenko et al., 2003, 2008; Minassian et al., 2004). Noninvasive magnetic stimulation over spinal vertebra offers an alternative method to activate the spinal circuitry (Ugawa et al., 1989; Fujishiro et al., 2000; Gerasimenko et al., 2010; Matsumoto et al., 2013). Afferent input is also a key factor in the control of locomotion. The fact that deafferentation reduces locomotor ability in spinalized animals (Goldberger, 1988; Lavrov et al., 2008; Nor- 
A

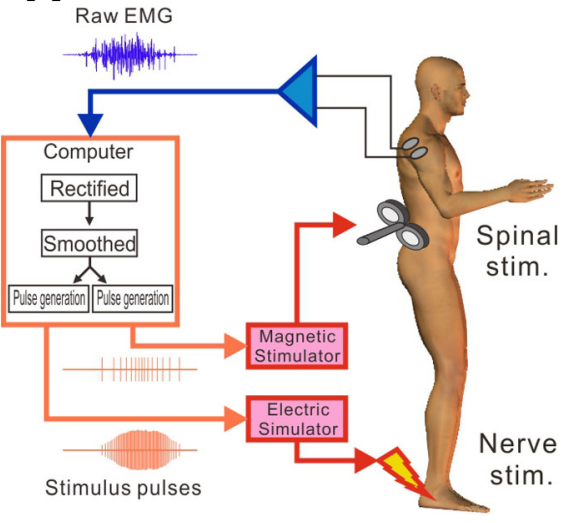

B
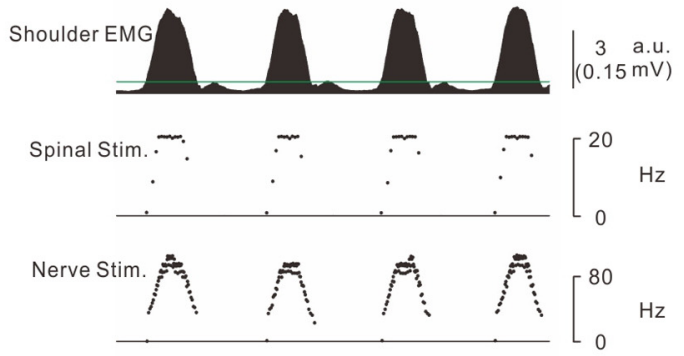

Nerve Stim
C

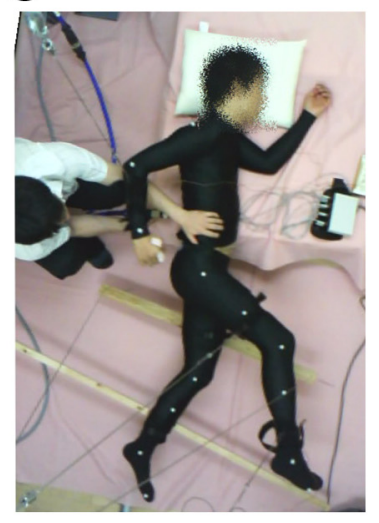

Figure 1. Experimental setup of artificial neural connection. A, Experimental setup of an ANC from the shoulder muscle to the lumbar locomotor center. Arm muscle-controlled magnetic and/or electrical stimulations are delivered over the lumbar vertebra and to the sural nerve at the foot, respectively. $\boldsymbol{B}$, Example of arm muscle-controlled magnetic and electrical stimulations. Magnetic stimulation (Spinal stim. on second trace) was delivered to the lumbar locomotor center, at a constant intensity, with frequency proportional to EMG amplitude (first trace) above a stimulation threshold (green line in first trace). Electrical stimulation (Nerve stim. on third and fourth traces) was delivered to the sural nerve of the foot, with current and frequency proportional to EMG amplitude above a stimulation threshold. C, A two-legged suspension system that was described previously (Selionov et al., 2009; Gerasimenko et al., 2010). The participant is positioned on their left side with the right (upper) leg supported directly in the area of the shank and the left (lower) leg placed on a brace attached to a horizontal board supported by vertical ropes secured to hooks in the ceiling. In this position, the participants were able to perform voluntary air-walking. The participants were instructed not to voluntarily intervene with the movements induced by stimulations.

ton and Mushawar, 2010) suggests the critical importance of sensory afferent inputs in the generation of locomotor pattern. Thus, the combination of spinal and peripheral nerve stimulation may drive the locomotor circuit more effectively.

A promising technique to compensate for the damaged pathway is the artificial neural connection (ANC) via a closed-loop computer interface (Jackson et al., 2006a, b; Moritz et al., 2008; Pohlmeyer et al., 2009; Ethier et al., 2012; Nishimura et al., 2013a, b). Studies have shown that monkeys can use cortical activity to control FES in muscles (Moritz et al., 2008; Pohlmeyer et al., 2009; Ethier et al., 2012) and spinal cord (Nishimura et al., 2013a), and restore volitional control of the paretic hand.

Together, these results suggest that an ANC beyond the lesion site using volitionally controlled stimulation of the locomotor circuit may compensate for the interrupted motor pathway. In the present study, we show that muscle-controlled stimulations, using noninvasive magnetic stimulation over the lumbar vertebra associated with electrical stimulation to the sural nerve, are able to induce volitional walking in healthy humans. This paradigm bypasses the interrupted pathways and reestablishes volitionally controlled walking in individuals with damage to the descending pathways to the lumbar locomotor center.

\section{Materials and Methods}

Participants. The experiments were performed in 10 male healthy volunteers (age, 26-52 years; height, $158-182 \mathrm{~cm}$; and weight, $55-80 \mathrm{~kg}$ ) in accordance with the Declaration of Helsinki. All procedures were approved in advance by the ethical committees of Fukushima Medical University, Fukushima, Japan (Approval No. 1278) and the National Institute for Physiological Sciences, Okazaki, Japan (Approval No. 12B009). All experiments were conducted at Fukushima Medical University. Written informed consent was obtained from all participants.

Artificial neural connection. To achieve an ANC that sends voluntary commands to the lumbar locomotor center and bypasses the thoracic spinal cord, muscle activity of an arm was converted to stimulus pulses. These pulses were used to trigger both magnetic stimuli delivered over the lumbar vertebra and electrical stimuli to the plantar cutaneous afferent nerve (Fig. 1A). The ANC was accomplished by a computer interface designed to encode the outline of full-wave rectified and moving aver- aged (250 ms window) surface EMG activity from a muscle, and to convert the encoded EMG activity ( $X$ [a.u.]) into electrical rectangular pulses. The amplitude and frequency of these pulses were determined by the level of the EMG activity from input muscle. Using output channels, participants were able to voluntarily alter the frequency of magnetic stimulation and the frequency and intensity of the peripheral nerve stimulation through the interface. If the input muscle activity $(X[$ a.u.]) was the above stimulus threshold ( $X_{t h}$ [a.u.], as indicated by Fig. $1 B$, green line on the first trace), the frequency $(f[\mathrm{~Hz}])$ and current $(I[\mathrm{~mA}])$ were modulated by the following equations:

$$
f=f_{0}+\frac{f_{g}}{X_{t h}} \cdot X,\left(f \leq f_{\text {Max }}\right)
$$

where $f_{0}=$ frequency at $X_{t h}[\mathrm{~Hz}], f_{\mathrm{g}}=$ gain of stimulus frequency, and $f_{\text {Max }}=$ maximum frequency $[\mathrm{Hz}]$.

$$
I=I_{0}+\frac{I_{g}}{X_{t h}} \cdot X,\left(I \leq I_{\text {Max }}\right)
$$

where $I_{0}=$ intensity at $X_{t h}[\mathrm{~mA}], I_{\mathrm{g}}=$ gain of stimulus intensity, and $I_{\text {Max }}=$ maximum intensity $[\mathrm{mA}]$.

Before each session, we measured the background noise level and the amplitude of the input EMG activity; then $X_{t h}, f_{g}$, and $I_{g}$ were arbitrarily set by the experimenter. $X_{t h}$ was set as a value at which muscle activity could be detected without contamination of background signal noise and stimulus artifact. The $X_{t h}$ was $\sim 7.9$ times the background EMG activity at rest, which completely excluded a trigger pulse produced by background activity contamination (Fig. $1 B$ ). Gains of stimulus frequency $\left(f_{g}\right)$ and intensity $\left(I_{g}\right)$ were also set as values at which $f_{\text {Max }}$ and $I_{\text {Max }}$ were obtained at the peak amplitude of input EMG activity.

Magnetic stimulation over the lumber vertebra (spinal stimulation). Stimulation over the lumbar vertebra was performed by a magnetic stimulator with a figure-eight (double $70 \mathrm{~mm}$ diameter) or circular $(90 \mathrm{~mm}$ diameter) coil (Magstim rapid; Magstim). The center of the figure-eight coil or the upper edge of the circular coil was placed at the intervertebral region. Before the main experimental session, we determined the optimal site for inducing walking-like behavior in each participant. The stimulus intensity was kept constant in each participant, and its range was set at $30 \%-60 \%$ of the maximum output of the magnetic stimulator. Stimulus frequency was modulated according to the equation shown above (Eq. 1) 


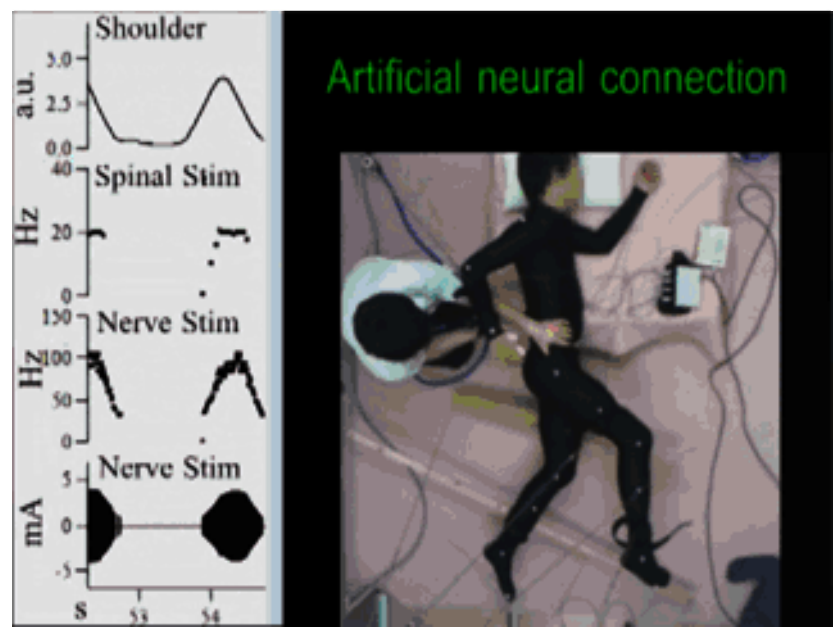

Movie 1. Volitional control of initiation and termination of walking-like behavior. Movie clip shows typical examples of walking-like behavior induced by shoulder muscle-controlled magnetic stimulation to the lumbar vertebra during volitional arm swing. The subject was asked to initiate and terminate the arm swing to control stimulations. To document the efficacy of the ANC, it was disconnected for several seconds in the "catch" trial. Data in Figure 2 were obtained from the subject in this movie clip.

between 1 and $20 \mathrm{~Hz}$. Participants confirmed that the magnetic stimulus over the vertebra was not painful.

Electrical stimulation of peripheral nerve (nerve stimulation). Peripheral nerve stimulation was provided by a $1 \mathrm{~ms}$ rectangular electric pulse to the sural nerve at the ankle (Bp Isolator; FHC). A pair of electrodes for sural nerve stimulation was placed on the lateral surface of the ankle, just posterior to the lateral malleolus. Stimulus frequency (Eq. 1) and intensity (Eq. 2) were modulated according to the equations shown above. The perceptual threshold was determined as the current at which the participant detected sensation initially when the intensity was gradually increased. In most cases, the ranges of current and frequency were perceptual threshold $\times 1-2.5 \mathrm{~mA}$ and $1-140 \mathrm{~Hz}$, respectively. The participants confirmed that the electrical stimulus to the sural nerve was not painful.

Experimental procedure. The experimental procedures were similar to those described previously (Selionov et al., 2009; Gerasimenko et al., 2010). The participants were in a semiprone position with the right side up on a comfortable bed (Fig. 1C; Movie 1). Legs were suspended by wires to keep the participants relaxed. This apparatus supported lowfriction motions of the legs and arms, so that the participant was able to readily perform leg movements in a horizontal plane. The participants were asked to keep their legs relaxed throughout the experiments and not to intervene against the leg movements induced by the spinal stimulation. Muscle activity was recorded from either a shoulder extensor muscle (posterior deltoid, "Shoulder" in first trace of Fig. 1B) during arm swing or a finger adductor muscle (first dorsal interosseous, see "Hand" in first trace of Fig. $3 A b$ ) during hand grip and was used to control the ANC. First, the participants were asked to induce leg movements by the ANC with controlled muscle activity. In the catch trial, stimulation was not given even though the participants maintained arm swings or hand grips (see Fig. 2, "Catch"). Next, they were instructed to modulate the step cycle from preferred ("Normal") to a faster cycle ("Faster") by voluntarily speeding up the arm swing cycle (see Fig. 4). Three stimulation conditions were compared: stimulation over the lumbar vertebra alone ("Spinal"), peripheral nerve stimulation alone ("Nerve"), and simultaneous spinal and peripheral nerve stimulation ("Nerve + Spinal"). Furthermore, to demonstrate the advantages of volitionally controlled stimulation, continuous stimulation at a constant frequency was also conducted ("Continuous"). The frequency of continuous stimulation was set at $f_{\max }$ in the ANC session. The range was between 15 and $20 \mathrm{~Hz}$, and the mean value was $16.1 \pm 1.8 \mathrm{~Hz}$ (Table 1 ). Both "Spinal" and "Nerve" stimulation was administered in the "Continuous" condition. As a control condition, we recorded EMG activities during voluntary air-stepping behavior without stimulation ("Voluntary"). Walking-like behaviors under these conditions were compared among the subjects. In 3 of 10 participants, the experiment was performed in an upright posture with a full or a partial body weight support by a walking frame of a body weight support system (Popo; Morito; see Movie 7). This system lightens the load of the participant's body weight on the legs via a crane attached to a walking frame. By using this system, participants can walk on the ground with body weight support. The amount of body weight support was changed gradually from full to partial (partial weight was $66 \pm 18 \%$ of body weight).

Recordings. To record muscle activities, bipolar surface electrodes (NM-512G; Nihonkoden) were placed on the muscle bellies of the rectus femoris (hip flexor), hamstrings (hip extensor), posterior deltoid, and first dorsal interosseous. EMG signals were amplified $(\times 1000$, MEG6116; NIHON KOHDEN) and bandpass filtered at 50-3000 Hz. All signals were converted to digital data via an $\mathrm{A} / \mathrm{D}$ converter system at a sampling rate of $5 \mathrm{kHz}$ for later off-line analysis (CED 1401 interface with Spike2 software; CED).

To record limb movements, a digital video camera was placed perpendicular to the floor (C905; Logicool). Frame rate and image resolution of the camera were $30 \mathrm{~Hz}$ and $640 \times 480$ pixels, respectively. Movement trajectories of the arms and legs were detected by reflective markers on each of the following: acromion (shoulder), the lateral epicondyle of the humerus (elbow), great trochanter (hip), lateral epicondyle of the femur (knee), and lateral malleolus (ankle) (Figs. $1 \mathrm{C}$ and $2 \mathrm{Ba}$ ).

Marker trajectories were digitized at $30 \mathrm{~Hz}$ and smoothed (moving average with $0.1 \mathrm{~s}$ interval) with built-in software (Dipp-Motion XD; DITECT).

Statistics. To quantify the ankle trajectory length during walking-like behavior, mean ankle trajectory length was analyzed for 5 cycles of arm swing. One-way ANOVA with repeated measures was performed to determine the significant differences in trajectory length among the "Shoulder," "Hand," "Continuous," "Catch," and "Voluntary" conditions. Post hoc multiple comparisons were conducted using Bonferroni correction (see Fig. 3B).

Two-way ANOVA with repeated measures was performed to determine the statistical differences in cycles. Two independent factors were limbs (leg step and arm swing) and speeds ("Normal" and "Faster"). To further determine the statistical difference between "Normal" and "Faster," paired $t$ tests were used with post hoc analysis (see Fig. 4C).

Significant differences in trajectory length between the "Nerve," "Spinal," and "Nerve + Spinal" conditions were also determined by one-way ANOVA with repeated measures. Post hoc multiple comparisons were conducted using Bonferroni correction (see Fig. 6B).

The significance of the $F$ values was obtained after Greenhouse-Geisser correction, when appropriate, and then a correction coefficient $\varepsilon$ was determined. Statistical significance level was set at $p<0.05$. All pooled values are reported as mean $\pm \mathrm{SD}$.

\section{Results}

Volitional control of a walking-like behavior via ANC

Figure $2 A$ shows a typical example of a walking-like behavior via the ANC controlled by shoulder muscle activity. The participants were asked to relax their legs and allow them to be controlled passively by the ANC generated from shoulder muscle activity during volitional arm swings. While the ANC was turned on (Fig. $2 A$, green bars), leg movement was not induced during participant relaxed the arm because the level of shoulder EMG activity was below the threshold for delivering stimulations (Fig. $2 A a, B a)$. The initiation of arm swinging immediately induced walking-like behavior in the legs (Fig. $2 A b, B b$ ). The walking-like behavior decreased gradually and stopped after the end of the arm swing (Fig. 2A; Movie 1). To document the efficacy of the ANC, the stimulations were stopped briefly during the "catch trial" for several seconds (Fig. 2A, white bar). During the catch trial, the arm swing failed to produce a walking-like behavior (see "catch trial" in Fig. $2 A c, B c)$. Typical recordings of leg kinematics, 
Table 1. Stimulus parameters ${ }^{a}$

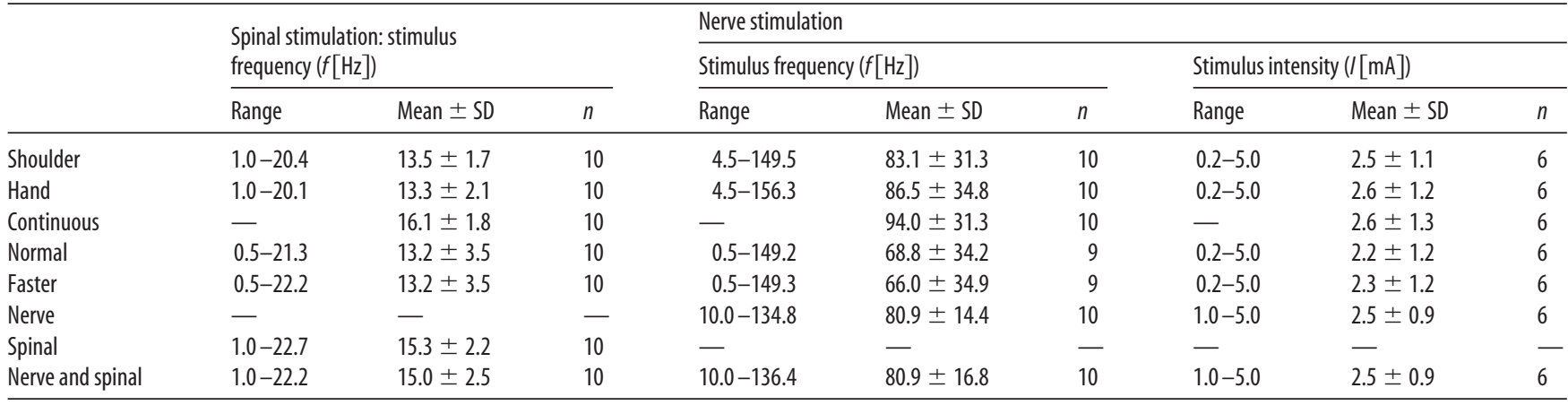

a Ranges and means of a stimulus burst are shown. These values were calculated from 5 cycles in all participants. In one subject, nerve stimulation was not performed in normal and faster tasks. Stimulus intensity of nerve stimulation was recorded in 6 participants.

A

a b

C

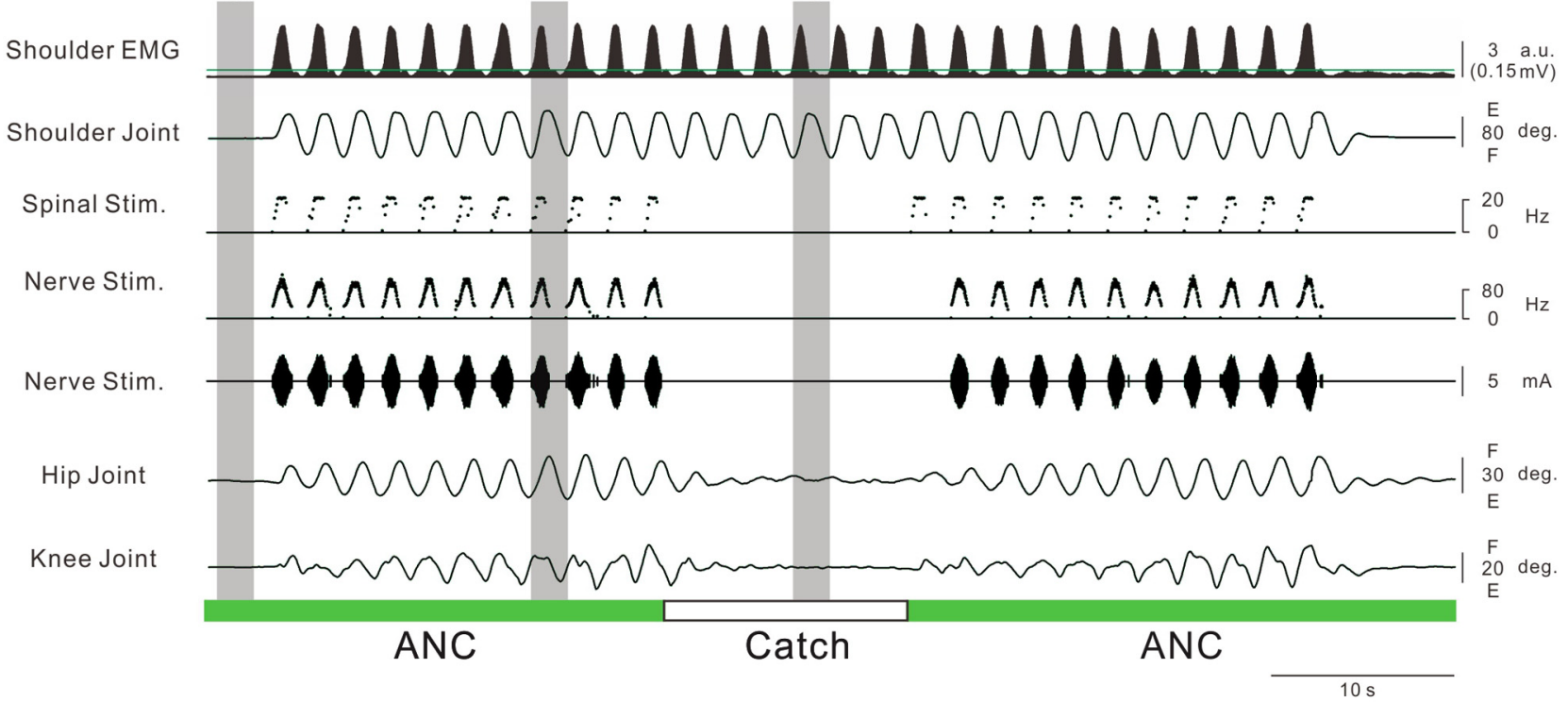

B

a

ANC

Before arm swing

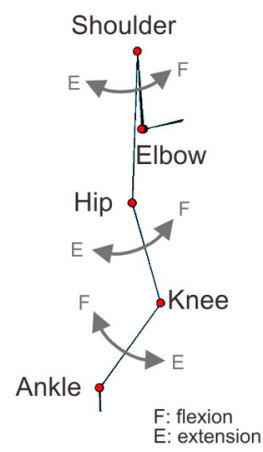

b

ANC

Arm swing

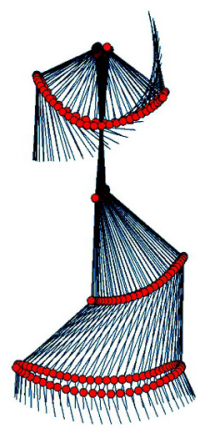

C

Catch

Arm swing

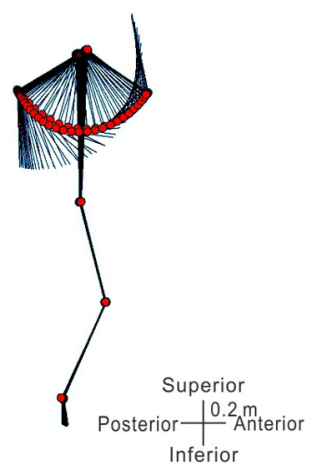

Figure 2. Volitional initiation and termination of walking-like behavior via an artificial neural connection. $\boldsymbol{A}$, Shoulder EMG (first trace) arm (second trace) and leg (sixth and seventh traces) kinematics and stimulations (third to fifth traces) obtained during Movie 1. Muscle-controlled magnetic (spinal stimulation on third trace) and electrical (nerve stimulation: the frequency and current are shown on fourth and fifth trace, respectively) stimulations were delivered to the intervertebral areas of $\mathrm{L} 2-\mathrm{L} 3$ and the sural nerve at the ankle, respectively. Gray hatched areas correspond to time windows for stick pictures in $\boldsymbol{B}$. Spinal stimulation (Spinal stim. on third trace) was delivered to intervertebral areas of $\mathrm{L} 2$ and $\mathrm{L} 3$ at $60 \%$ of maximum intensity with frequency ( $f[\mathrm{~Hz}]$ ) proportional to muscle activity $\left(X\left[\right.\right.$ [a.u.]) above a stimulation threshold $\left(X_{t h}\right.$ [a.u.]), which is indicated by the green line on the first trace $\left(f=1+6.7 X, f \leq 20, X_{\text {th }}=0.6(0.03 \mathrm{mV})\right)$. Nerve stimulation was delivered to the sural nerve at the ankle with frequency (Nerve stim. on fourth trace, $\left.f=30+16.7 X, f \leq 100, X_{t h}=0.6(0.03 \mathrm{mV})\right)$ and current $(I[\mathrm{~mA}]$, Nerve stim. on fifth trace: $I=2+1.7 X$, $I \leq 9, X_{t h}=0.6(0.03 \mathrm{mV})$ ) proportional to muscle activity above the given threshold as well. $\boldsymbol{B}$, Stick pictures showing induced walking behavior with ANC (green bars in $\left.\boldsymbol{A}\right)$ before $(\boldsymbol{B a})$ and during arm swing (Bb) and without ANC ("catch trial," white bar in $\boldsymbol{A}$ ) during arm swing (BC). 
A

\section{a}

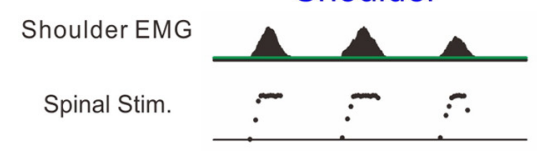

Hip Angle

Knee Angle

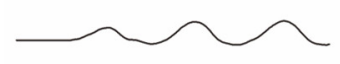

Ankle Trajectories

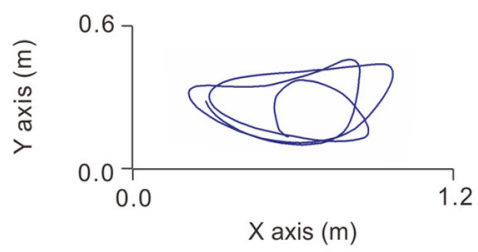

C

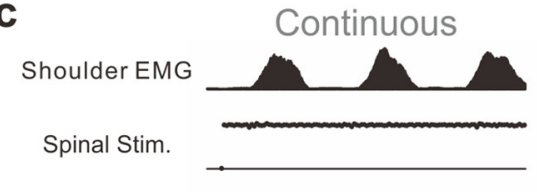

Hip Angle

Knee Angle

Ankle Trajectories

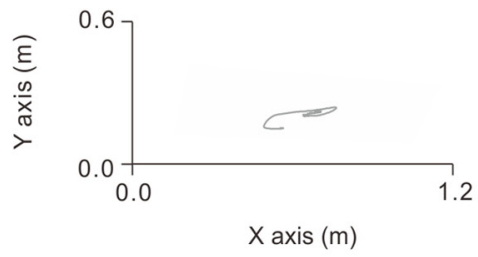

B

Trajectory length

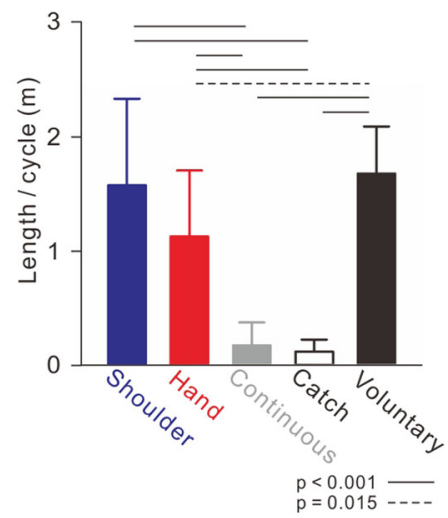

b Hand

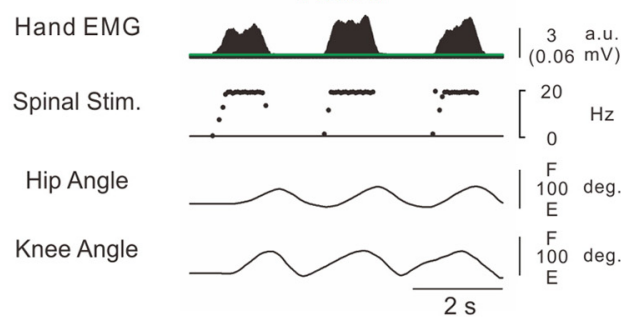

Ankle Trajectories

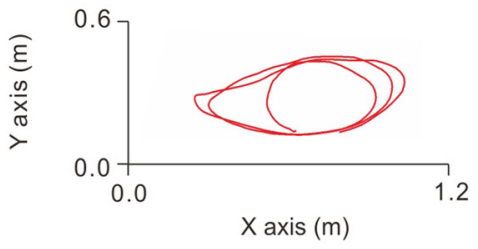

d Voluntary

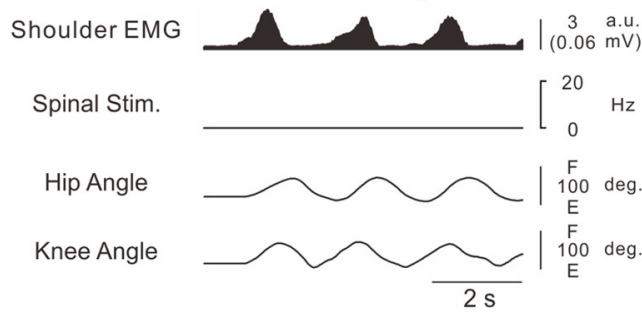

Ankle Trajectories

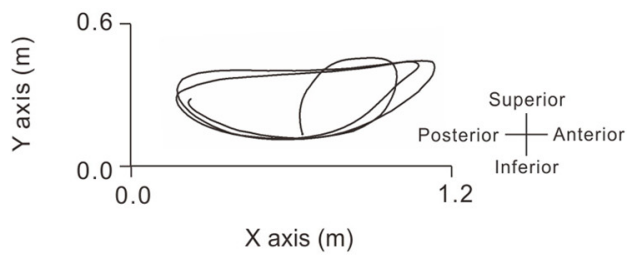

Figure 3. Ankle trajectories induced by different controllers. $\boldsymbol{A}$, Typical recordings of stimulation patterns, observed joint angles, and ankle trajectories. Aa, Muscle-controlled stimulations of the shoulder muscle. $\boldsymbol{A} \boldsymbol{b}$, Muscle-controlled stimulations of the hand muscle. $\boldsymbol{A} \boldsymbol{c}$, Continuous repetitive stimulations at constant frequency (18 $\mathrm{Hz})$. $\boldsymbol{A d}$, Voluntary air-stepping behavior without stimulations. The spinal stimulus intensity was fixed at $50 \%$ of maximum output, and spinal stimulation was applied over the intervertebral region of Th12-L1. Stimulus parameters were as follows: spinal stimulation $\left(f=1+13.3 X, f \leq 18, X_{t h}=0.3(0.01 \mathrm{mV})\right)$. $\boldsymbol{B}$, Averages and SDs of trajectory length for the different conditions $(n=10)$. Ankle trajectory length was analyzed for 5 cycles of arm swing. One-way ANOVA showed significant differences between these trajectory lengths $\left(f_{(1.571,14.141)}=42.902, p<0.001\right)$. Black horizontal lines indicate probabilities between the given values obtained from post hoc multiple comparisons: solid lines indicate $p<0.001$; dashed line indicates $p=0.015$ ). 


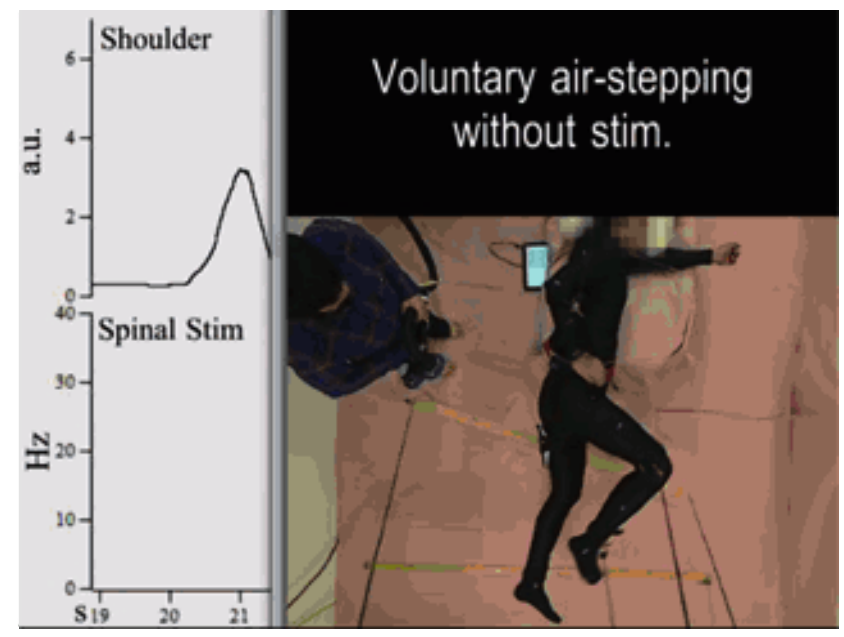

Movie 2. Comparison between voluntary air-stepping behavior without stimulations and walking-like behaviors controlled by shoulder muscle. Movie clip shows a typical example of voluntary air-stepping without stimulations and walking-like behavior induced by shoulder muscle-controlled stimulation. The subject was asked to mimic the walking behavior without stimulation and to swing the arm to control the stimulation. Data in Figure $3 \mathrm{Aa}$, Ad were obtained from the subject in this movie clip.

stimulation, and ankle trajectory in 3 step cycles induced by shoulder muscle-controlled stimulation are presented in Figure $3 A a$. The shape of the ankle trajectory in ANC-controlled walking-like behavior was identical to that in voluntary airstepping (compare Fig. $3 A a$ with Fig. $3 A d$; Movie 2). All participants were able to induce the walking-like behavior voluntarily and control its initiation and termination via the ANC. The averaged trajectory length per swing cycle was calculated from all participants (Fig. 3B). The ankle trajectory of walking-like behavior was equivalent to that of voluntary walking, whereas that in the catch trial was markedly shorter. The optimal sites for inducing a walking-like behavior were positioned at the intervertebral levels of Th12-L1 $(n=1)$, L1-L2 $(n=3)$, or L2-L3 $(n=6)$.

Volitional control of walking-like behavior could also be controlled by hand muscle activities, which was not involved in the arm swing during walking (Fig. 3Ab; Movie 3). The shape of the ankle trajectory during the walking-like behavior controlled by hand muscle was identical to that of the voluntary air-stepping and shoulder-controlled walking (compare Fig. $3 A a, b$ with Fig. $3 A d)$. The average trajectory length induced by hand muscle activities was significantly longer than that during the catch trial but shorter than the voluntary air-stepping (Fig. $3 B$ ). The trajectory length controlled by hand muscle tended to be shorter than that controlled by shoulder muscle, although their difference was not statistically significant. The means and ranges of output frequency and intensity during these stimulus bursts were also comparable between both tasks (Table 1). In contrast, continuous stimulations through the ANC at a constant frequency failed to induce any walking-like behavior in 8 of 10 participants (Fig. 3Ac; Movie 4). The trajectory length induced by continuous stimulation was significantly shorter than other muscle-controlled walking-like behaviors (Fig. 3B).

Participants were able to volitionally control the step cycle via the ANC. Figure 4 shows a typical example of shoulder muscle EMGs, pulse waveforms of stimulations, and induced kinematics in the arm and leg. When the arm swing cycle was increased voluntarily from normal (Fig. 4A, left, gray bar) to faster (Fig. 4A, red bar), the step cycle also increased accordingly. However, range of motion of lower limb was a little smaller during faster

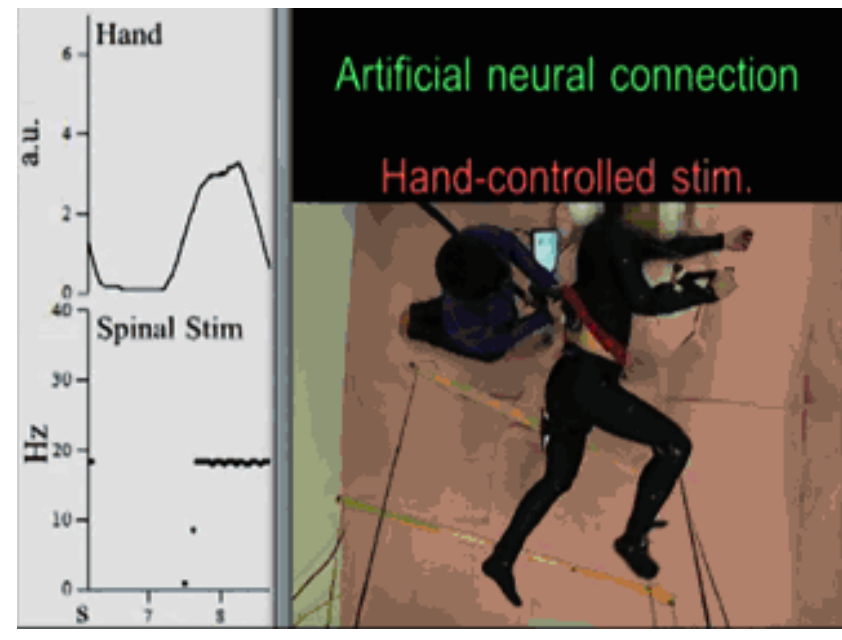

Movie 3. Volitional control via hand muscle. Movie clip shows a typical example of walking like behavior induced by hand muscle-controlled stimulation. Subject was asked to grip the hand repeatedly to control stimulations. Data in Figure $3 A b$ were obtained from the subject in this movie clip.

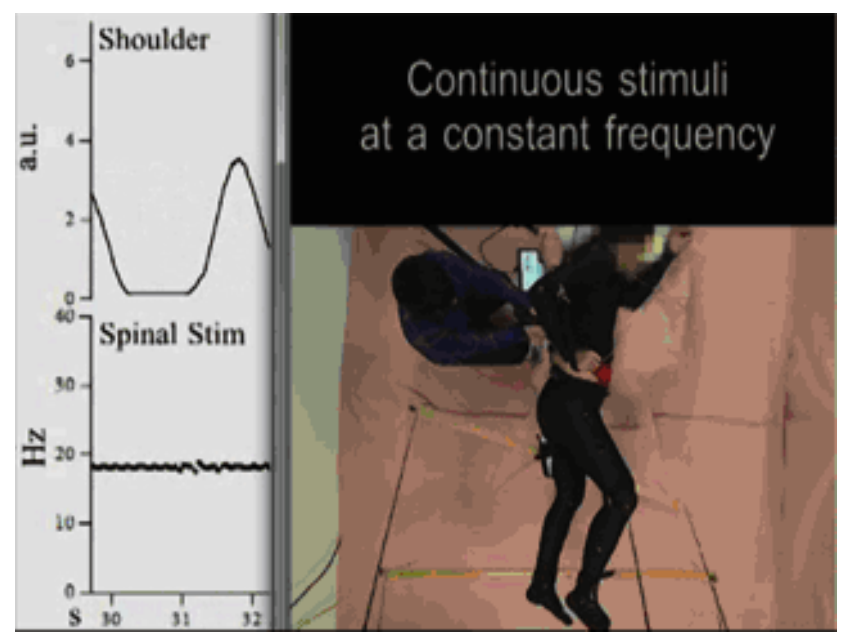

Movie 4. Continuous stimulations. Movie clip shows a typical example of behavior when continuous stimulations at a constant frequency were applied. The subject was asked to relax the legs during arm swings and stimulations. Figure $3 A c$ was obtained from the subject in this movie clip.

step cycle. In turn, slowing the arm swing cycle decreased the step cycle (Fig. 4A, right, gray bar; Movie 5). To document interlimb coordination with the ANC, we examined phase differences between the arm swing and leg step. Phase analysis showed that the shoulder and hip joint angles were approximately antiphasic (Fig. $4 B$ ), and the leg step cycle and arm swing cycle were identical regardless of cycle (Fig. $4 C$ ).

We recorded the EMG activities from several leg muscles during walking-like behavior using hand-controlled spinal stimulation. Typical recordings of stimulation, kinematics, and EMG activities (Fig. 5A) and a stick diagram in both legs (Fig. 5B) show alternative EMG bursts between the hip flexor and extensor muscles during the ANC-controlled walking-like behavior. The EMG bursts of the right hip flexor and the left hip extensor muscles corresponded to each stimulus burst. The EMG bursts in the right hip extensor and the left hip flexor muscles appeared reciprocal to those of the right hip flexor and the left hip extensor muscles. These coordinated EMG bursts between extensor and flexor muscles in both legs generated a walking-like behavior, which 

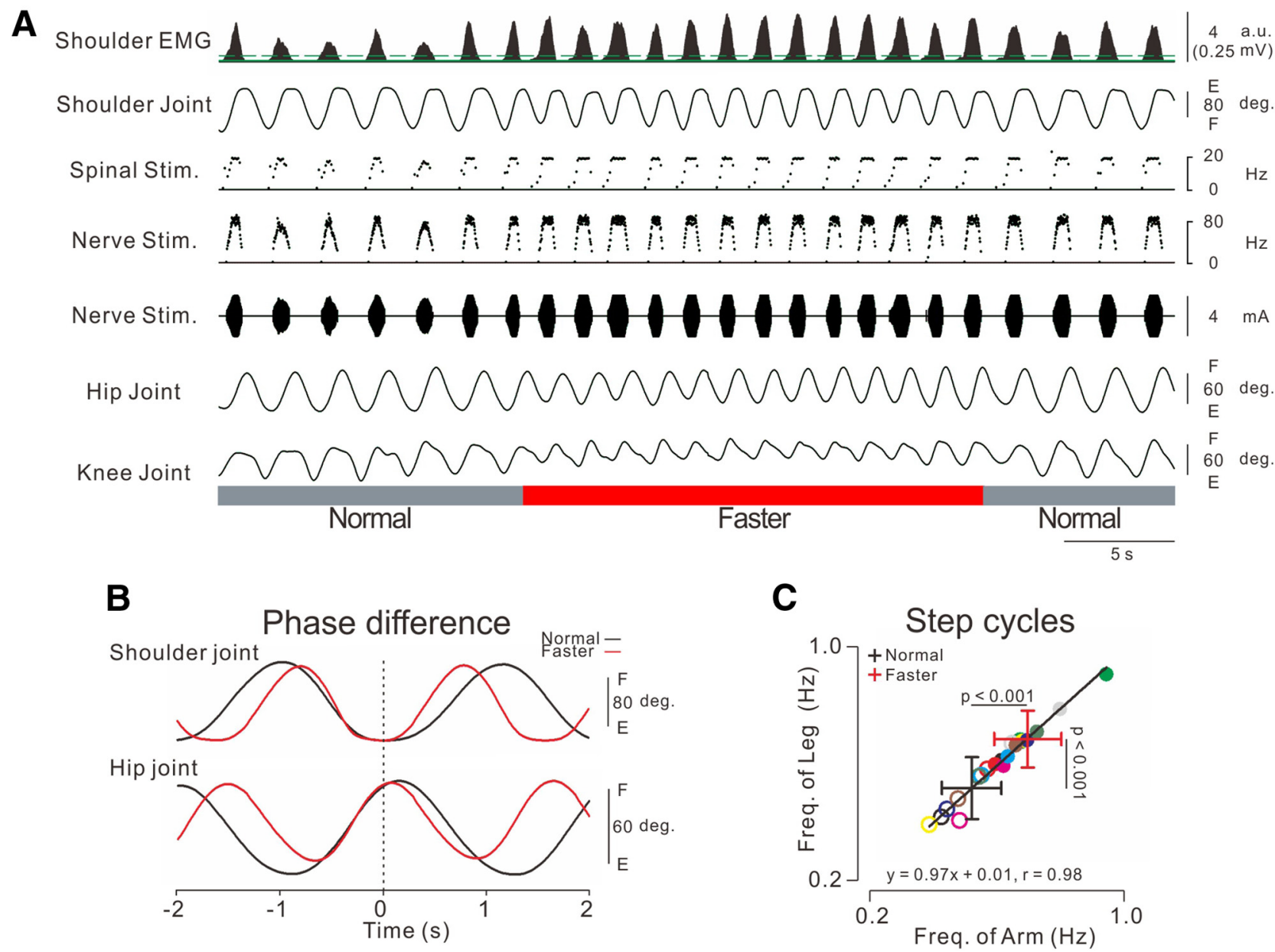

Figure 4. Volitional control of the step cycle. $A$, Typical example of stimulations and observed kinematics during participant controlled step cycles, with normal and faster steps shown in gray and red bars, respectively. Stimulus parameters were as follows: spinal stimulation: $f=1+10 X, f \leq 18, X_{t h}=0.1$ (green solid line on first trace indicates $0.01 \mathrm{mV}$ ); nerve stimulation: $f=25+50 X$, $f \leq 100, X_{t h}=0.5$ (green dotted line on first trace indicates $0.03 \mathrm{mV}$ ) $I=2.2+4 X, I \leq 8.5, X_{t h}=0.5 . B$, Averaged traces of shoulder and hip joint kinematics during normal (black trace) and faster (red trace) steps for 5 cycles. These data were obtained during the respective times shown by the gray (normal) and red (faster) bars in $A$. C, Linear regression analysis between arm swing and leg step cycles. Open and filled circles represent individual values in each participant during normal and faster cycles, respectively. Averaged values and SDs are indicated by the positions and the lengths of cross symbols, respectively. Two-way ANOVA [speed (Normal and Faster) $\times \operatorname{limb}$ (arm swing and leg step)] showed significant effects for speed $\left(f_{(1,9)}=44.515, p<0.001\right)$. There were no significant differences for $\operatorname{limb}\left(f_{(1,9)}=1.866, p>0.05\right)$ and cycle $\times \operatorname{limb}\left(f_{(1,9)}=1.496, p>0.05\right)$.

indicates that the ANC is able to reproduce some interlimb and intralimb coordinated walking-like behaviors.

\section{Additional afferent inputs}

Peripheral nerve stimulation to the foot enhanced the above walking-like behavior (Fig. 6; Movie 6). Figure 6 shows typical recordings of joint angle and ankle trajectories of walking behavior induced by three kinds of stimulation: "Nerve," "Spinal," and "Nerve + Spinal." "Nerve" stimulus induced walking-like behavior in only one participant ("Nerve" in Fig. 6A, "Nerve"). In all 10 participants, "Spinal" stimulation induced a walking-like behavior (Fig. 6A, "Spinal"). The ankle trajectory was enlarged when muscle-controlled nerve stimulation was superimposed on the spinal stimulation (Fig. 6A, compare "Spinal" and "Nerve + Spinal"). Figure $6 B$ shows pooled data of the induced trajectory length in the three conditions. The trajectory length in "Spinal" and "Nerve + Spinal" was significantly longer than that in "Nerve." The trajectory length in "Nerve + Spinal" was significantly longer than that in "Spinal." The means and ranges of output stimulus frequency ( $f$ of both spinal and nerve stimulation) or intensity (I of nerve stimulation) did not differ signifi-

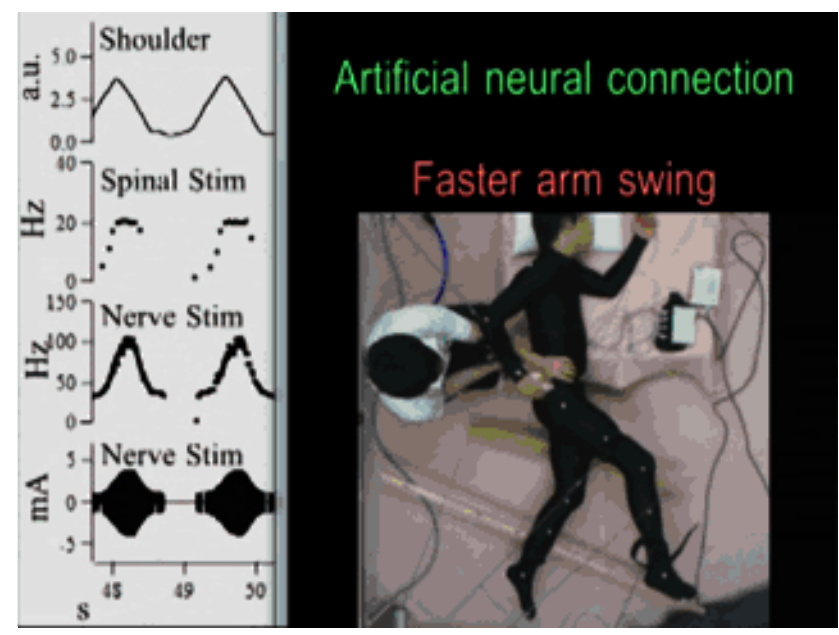

Movie 5. Volitional control of step cycle frequencies. Movie clip shows a typical example of volitional control of step cycle via ANC. The subject was asked to change the step cycle from the normal to the faster cycle by voluntarily changing the arm swing cycle. Stimulus parameters were as follows: spinal stimulation $\left(f=1+6.6 X, f \leq 20, X_{t h}=0.6(0.03 \mathrm{mV})\right)$ and nerve stimulation $(f=30+$ $\left.16.6 X, f \leq 100, X_{t h}=0.6(0.03 \mathrm{mV}) ; I=2+1.6 X, I \leq 9, X_{t h}=0.6(0.03 \mathrm{mV})\right)$. 
A

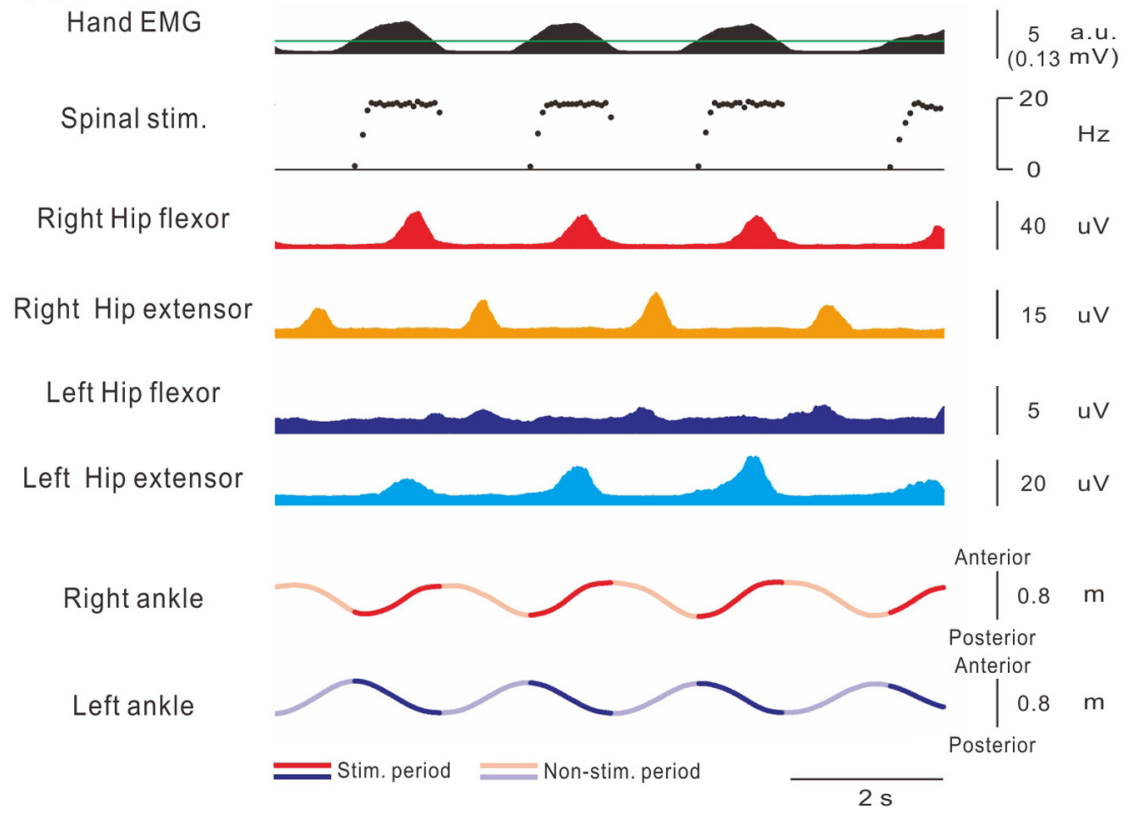

B
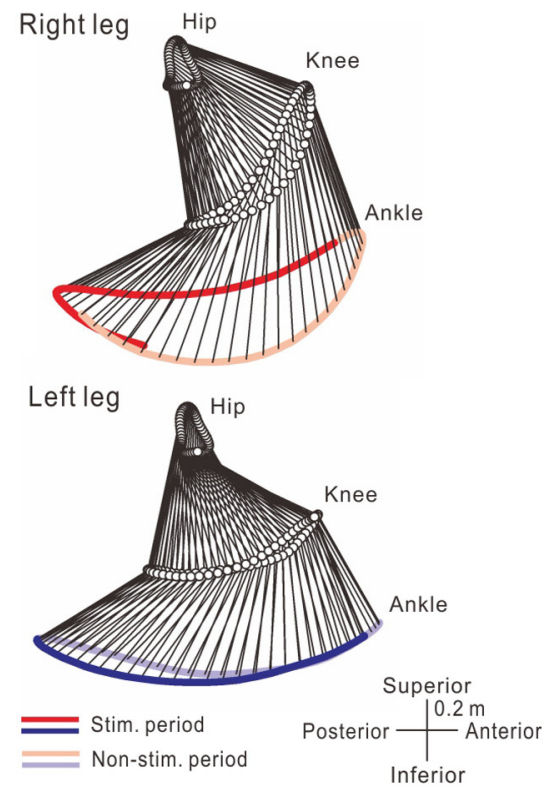

Figure 5. The activity patterns in leg muscles during walking-like behavior. $A$, Typical recordings of muscle activities and observed kinematics of the legs. Stimulus parameters were as follows: spinal stimulation: $f=1+7.7 X, f \leq 18, X_{\text {th }}=1.3$ (green line indicates $0.03 \mathrm{mV}$ ). These traces of leg muscle activities were rectified and smoothed with a $0.1 \mathrm{~s}$ interval. Hip flexors and extensors were the rectus femoris muscle and biceps femoris muscle, respectively. $\boldsymbol{B}$, Stick diagram decompositions ( $33 \mathrm{~ms}$ interval between sticks) during walking-like behavior induced by muscle-controlled stimulation. Each stick was composed by hip, knee, and ankle markers. Dark and undertint color of both ankle trajectories represents time periods during and between stimulus bursts, respectively.

cantly between the tasks (Table 1). Thus, additional peripheral nerve afferent inputs enhanced the walking-like behavior.

\section{"Walking" at upright posture}

Movie 7 shows a typical example of walking-like behavior in upright posture via the ANC. In this condition, the participant controlled the spinal stimulation (50\% of maximum intensity) over the L1-L2 intervertebral area using the hand muscle activity ( $f=$ $1+100 X, f \leq 20, X_{t h}=0.2$ ). During full body weight support at upright posture, the participant was asked to induce the behavior through the ANC while keeping their legs relaxed. Air-stepping behavior was induced even under gravity (Movie 7). The amount of body weight support was gradually reduced by the experimenter while the participant tried to control air-stepping behavior continuously. When the amount of body weight support was reduced to $47 \%$ body weight support and the participant's foot touched the ground, participants could "walk" forward (Movie 7). The forward walking movement was disrupted by disconnection of the ANC stimulus (catch trial), and the participants restarted "walking" forward when afferent inputs were reconnected. All participants tested were able to "walk" forward at upright posture, as well as at a semiprone position.

\section{Discussion}

Our results provide the first demonstration of volitionally controlled walking via a closed-loop computer interface. The present stimulation paradigm induced a well-coordinated walking-like behavior by eliciting right-left and flexor-extensor coordinated muscle activities. Stimulation also maintained the interlimb and intralimb coordination. Moreover, subjects controlled the initiation and termination of walking, as well as the step cycles voluntarily. We have shown that the ANC is able to compensate for interrupted function of the descending pathways by sending an intentionally encoded command to the preserved locomotor center at the lumbar spinal cord. The ANC may help restore volition- ally controlled walking in individuals with SCI at the upper thoracic level.

\section{Magnetic stimulation over lumbar vertebra induces functional locomotion}

Neural circuits in the spinal cord generate functional and complex limbs movements. Intraspinal electrical stimulation offers coordinated movements and evoke synergistic muscle responses in multiple muscles (Mushahwar and Horch, 2000a, b; Mushahwar et al., 2000; Mussa-Ivaldi and Bizzi, 2000; Saigal et al., 2004; Moritz et al., 2007; Nishimura et al., 2013a). Tonic stimulation via epidural (Dimitrijevic et al., 1998; Gerasimenko et al., 2003, 2008; Minassian et al., 2004, Ichiyama et al., 2005; Harkema et al., 2011; van den Brand et al., 2012) or intraspinal electrodes (Barthélemy et al., 2006, 2007) has been reported to induce locomotor activities. Bilateral locomotion is also induced by electrical stimulation of dorsal roots (Barthélemy et al., 2007). These previous reports suggest that the spinal neural network, including afferent fibers, may be able to generate a locomotor activity. These stimulations activate spinal circuits directly. The magnetic stimulation over the lumbar vertebra, however, most probably activates afferent fibers of the dorsal roots nonselectively through induced eddy currents (Ugawa et al., 1989; Fujishiro et al., 2000; Matsumoto et al., 2013) and indirectly activates spinal circuits. Magnetic stimulation must be much weaker than the stimulations reported to induce walking movements by tonic electrical stimulation. This strength of magnetic stimulation may explain our failure of locomotor induction by tonic stimulation. It remains unclear what neuronal elements were driven by magnetic stimulation on lumbar vertebra. It has documented that Ia afferent activated by vibration of the patellar ligament induced locomotor-like stepping (Gurfinkel et al., 1998). In addition, cutaneous afferent around lateral foot activated by tonic electrical stimulation of sural nerve also induces locomotor-like stepping (Selionov et al., 2009). Indeed, additional cutaneous afferent 
A

Nerve

Spinal

Nerve+Spinal
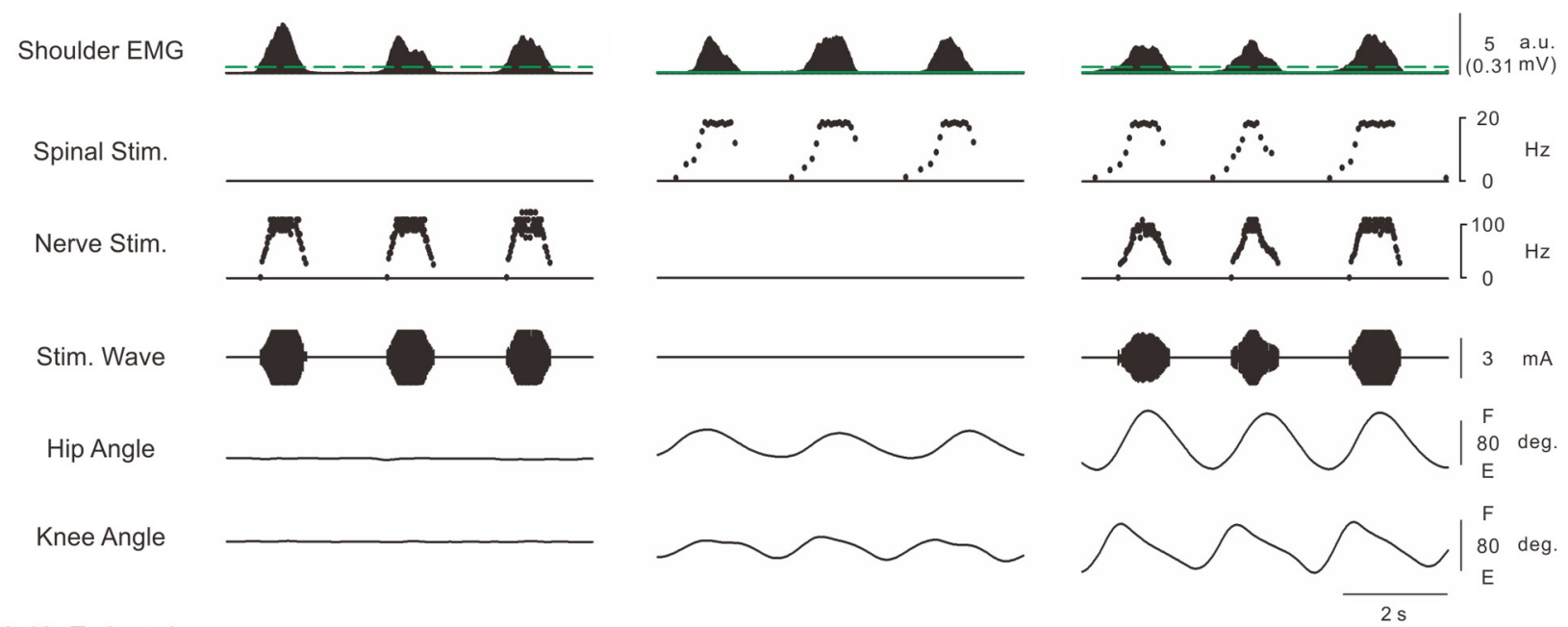

Ankle Trajectories
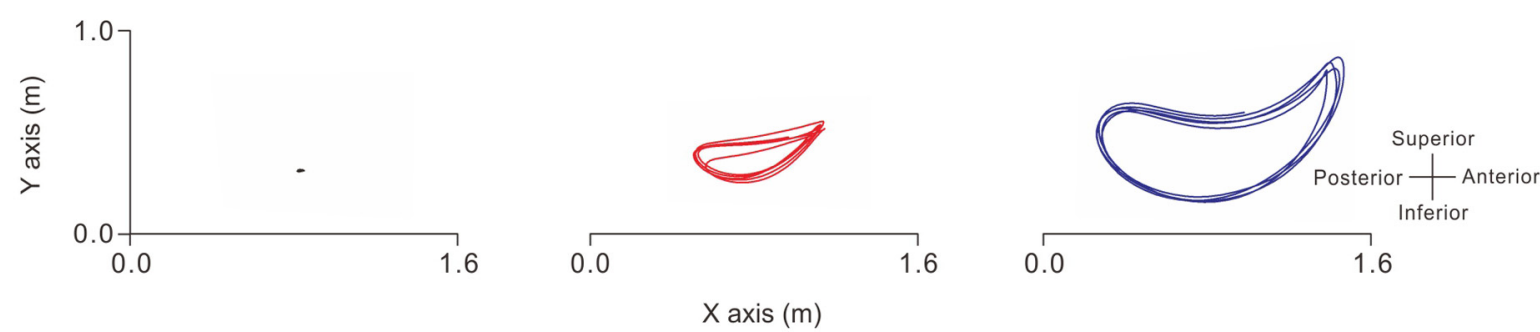

B

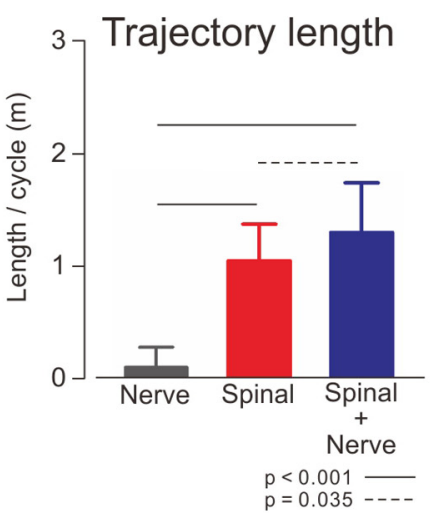

Figure 6. Effect of peripheral afferent input on the induced walking-like behavior. $\boldsymbol{A}$, Typical recordings of stimulation patterns, joint angles, and ankle trajectories under three conditions obtained from the participant in Movie 6. There were three stimulus conditions: sural nerve stimulation alone ("Nerve"), spinal stimulation alone ("Spinal"), and both stimulations together ("Nerve + Spinal"). The shoulder EMG controlled stimulations in all three conditions. In this participant, spinal stimulation was applied over the intervertebral area at the L2-L3 level, and its intensity was fixed at $60 \%$ of maximum output. Stimulus parameters were as follows: nerve stimulation $\left(f=25+50 X, f \leq 100, X_{t h}=0.5 ; I=2.2+4 X, I \leq 8.5, X_{t h}=0.5 ;\right.$ green dotted line on first trace indicates $0.03 \mathrm{mV}$ ) and spinal stimulation $\left(f=1+10 X, f \leq 18, X_{\text {th }}=0.1\right.$ (green solid line on first trace indicates $\left.0.01 \mathrm{mV}\right) . \boldsymbol{B}$, Averages and SDs of trajectory length $(n=10)$. Ankle trajectory length was analyzed for 5 cycles of arm swing. One-way ANOVA showed significant difference between these trajectory lengths $\left(f_{(2,18)}=98.183, p<0.001\right)$.

stimulation enhanced locomotor-like behavior in our results. Based on these arguments, we consider it most likely that the large-diameter muscle and cutaneous afferent nerves of the dorsal roots were activated by the magnetic stimulation, which drive the lumbar locomotor center.

The optimal site to induce walking-like behavior was located at Th12-L3 in the present study. The reason for the interindividual difference in the best site of stimulation is unclear. It may depend on the subject's posture, daily walking pattern, or other factors affecting waking. Such factors may determine the best site of stimulation.

\section{Volitionally controlled stimulation}

The development of FES to muscle has been investigated to restore voluntary limb function (Peckham et al., 2001; Popovic et al., 2001). In a typical FES system, the patient uses residual proximal limb movements or muscle activity to trigger preprogrammed patterned stimulation of paralyzed muscles for the 


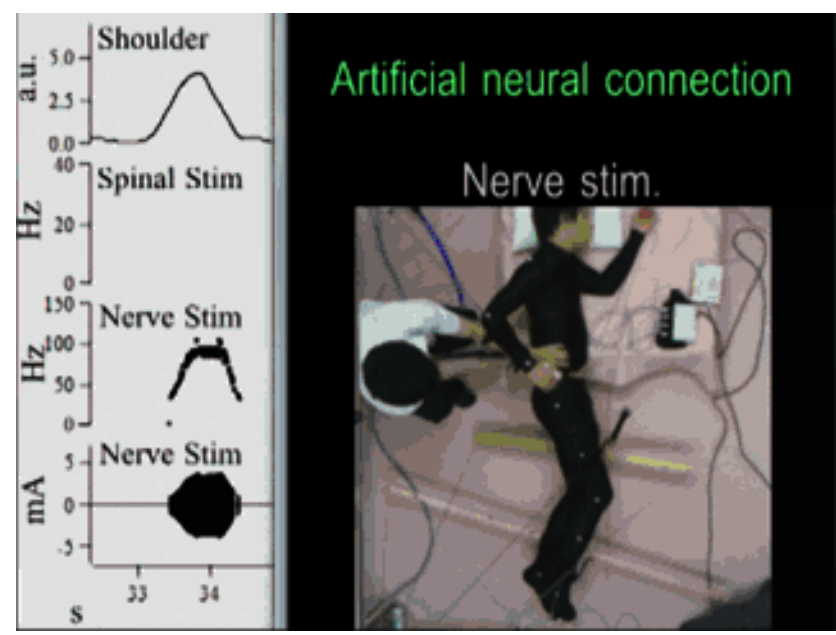

Movie 6. Cutaneous afferent input enhances walking-like behavior. Movie clip shows the effect of cutaneous afferent input on the induced walking-like behavior. Nerve stimulus alone (Nerve stim.), spinal stimulus alone (Spinal stim.), and both nerve and spinal stimuli (Nerve + Spinal) were applied for controlling behavior. Stimulus parameters were as follows: spinal stimulation $\left(f=1+6.6 X, f \leq 20, X_{t h}=0.6(0.03 \mathrm{mV})\right)$ and nerve stimulation $(f=30+$ $\left.16.6 X, f \leq 100, X_{\text {th }}=0.6(0.03 \mathrm{mV}) ; I=2+1.6 X, I \leq 9, X_{\text {th }}=0.6(0.03 \mathrm{mV})\right)$.

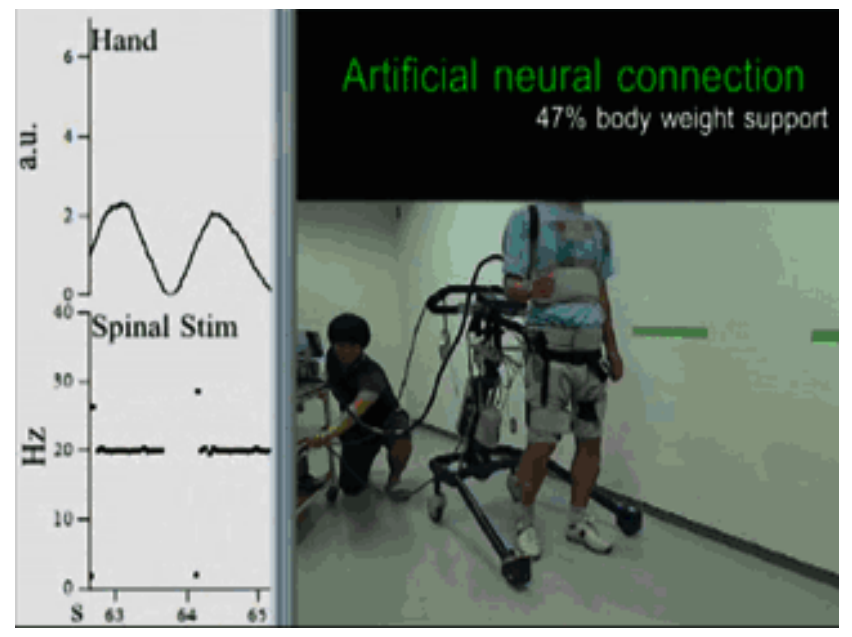

Movie 7. Walking in upright posture. Movie clip shows typical example of walking-like behavior in an upright posture. Stimulation was controlled by hand muscle activity during volitional hand grips. The subject was lifted up by a walking frame to maintain an upright posture and asked to walk forward by controlling the stimulation with body weight support. Stimulus parameters were as follows: spinal stimulation $\left(f=1+13.3 X, f \leq 20, X_{\text {th }}=0.3\right.$ $(0.01 \mathrm{mV}))$ and nerve stimulation $\left(f=30+60 X, f \leq 100, X_{\text {th }}=0.3(0.01 \mathrm{mV}) ; I=2+1.6 X\right.$, $I \leq 8, X_{t h}=0.3(0.01 \mathrm{mV})$ ).

production of one or two stereotyped movements. However, restoring coordinated movements of paralyzed limbs with FES remains problematic (Popovic et al., 2001). Stimulation of peripheral nerves or muscles often evokes single joint movements. Instead, many types of multijoint-coordinated movements, including gait, are required in our daily life. Here, we developed an ANC system that allows participants to control the initiation, termination (Fig. 2), and step cycles (Fig. 4) of walking-like behavior volitionally. The volitionally controlled walking behavior in our paradigm is superior to the uncontrollable walking behaviors of the legs induced by preprogrammed stimulation. Some invasively recorded brain signals have been used to control signals for external devices (Wessberg et al., 2000; Serruya et al., 2002; Carmena et al., 2003). Instead of relying on invasively re- corded cortical signals, we used muscle activities as a surrogate of brain activity. Volitionally controlled muscle activities are more robust than electrical brain activities and easy to record and have few artifacts associated. They must expand the sources of control signals for closed brain-computer interface substantially (Nishimura et al., 2013a).

Whereas a continuous tonic stimulation rarely induced walking-like behavior similar to previous reports (Barthélemy et al., 2007; Gerasimenko et al., 2010), volitionally controlled stimulation elicited alternative EMG bursts in bilateral flexor and extensor muscles, which produced a walking-like behavior in all participants (Fig. 5). Consistently, rhythmic stimulation easily induced locomotor activity in spinalized cat (Barthélemy et al., 2007). During locomotion in cats, reticulospinal neurons were modulated by the locomotor rhythm (Drew et al., 1986; Perreault et al., 1993; Matsuyama and Drew, 2000). Such a modulated descending command may reach the spinal circuit. Our volitionally modulated stimulus pattern may be comparable with natural locomotor descending inputs to the spinal locomotor circuit, which explains our finding that the volitionally modulated stimulation was able to induce a walking-like movement.

We should consider the possibility that the locomotor arm movement contributes to the generation of locomotor leg movements via interlimb neural coupling between the arm and leg. Locomotor arm movement facilitated an induction of locomotor leg muscle activity in intact humans (Huang and Ferris, 2004) but did not induce leg muscle activity in complete SCI individuals (Kawashima et al., 2008). In our results, the trajectory length controlled by hand tended to be shorter than those controlled by shoulder, although there was no significant difference between both tasks (Fig. 3B). In addition, tonic magnetic stimulation with arm swing did not induce a walking-like behavior (Movie 4). Therefore, interlimb neural coupling may be weak or not involved in our condition.

One limitation of our study is that we conducted the experiments in intact participants. The participants were asked to inhibit the volitional control of their legs and confirmed the disruption of walking-like behavior when the stimulation was turned off ("catch trial" in Figs. 2 and $3 B$ ). However, our experimental design cannot fully exclude some subliminal direct control of the behavior by innate descending pathways. Further study needs to investigate whether the ANC controls the lumbar locomotor center in individuals with a complete SCI.

\section{Cutaneous afferent input enhances the walking-like behavior} Cutaneous afferents have a powerful influence on spinal locomotor circuits (Bouyer and Rossignol, 2003; Rossignol et al., 2006), and electrical sural nerve cutaneous afferent stimulation modified the walking pattern (Zehr et al., 1998). We used the sural nerve stimulation to activate the flexor reflex pathway, which activates flexor muscles in the target limb and extensor muscles in the contralateral limb. Cutaneous afferent inputs enlarge the subliminal excitability of the spinal circuit in our paradigm. Indeed, additional muscle-controlled cutaneous afferents to the foot enhanced a walking-like behavior (Fig. 6, "Nerve + Spinal"). Electrical stimulation to the sural nerve activates only cutaneous afferents around the lateral side of the foot. Removing a partial cutaneous afferent around the foot did not abolish walking (Bouyer and Rossignol, 2003; Dorofeev et al., 2008). Volitionally controlled cutaneous afferent input around the foot alone may be insufficient to drive the locomotor center. 


\section{Clinical application}

The fact that our paradigm could be controlled by various muscles (Fig. 3) suggests that this stimulation paradigm may be applied to many individuals with several kinds of disorders or several lesion sites. The stimulation may be controlled by EMGs from any residual muscle. Additionally, the induced behavior through the ANC was sufficient to allow the participant to "walk" forward on the ground over gravity while the body weight was partially supported (Movie 7). This ability supports the clinical usefulness of this method. However, because the input muscle activities were smoothed for $250 \mathrm{~ms}$, some delay appears from input to stimulation. This delay may be critical for the adjustment of walking behavior when some external perturbations occur.

Therapeutic electrical stimulation to the peripheral or central nervous system has been shown to promote functional recovery after injury (Plautz et al., 2003; Popovic et al., 2004; Kasten et al., 2013). Our paradigm may activate the locomotor center directly or indirectly and may be used to restore gait or strengthen neuromuscular systems of locomotion in rehabilitation. A recent case report has shown that preprogrammed tonic electrical stimulation via chronically implantable epidural spinal cord stimulation unit induced stepping-like EMG bursts in a patient with an SCI (Harkema et al., 2011). Implementation of ANC with a portable or implantable bidirectional neural interface may enable patients to control movements volitionally and to perform various movements, including free behavior. The autonomous "Neurochip" system, which is sufficiently small for chronic implant, discriminates brain or muscle activity and delivers electrical stimulation during free behavior (Mavoori et al., 2005; Zanos et al., 2011). Such small-sized autonomous low-power circuits may allow subjects to practice continuously with an ANC outside the laboratory, without requiring a large magnetic stimulator or external devices, such as the exoskeletal robot. Furthermore, long-term exposure to an ANC could induce reorganization of cortical and spinal circuitry (Jackson et al., 2006a; Lucas and Fetz, 2013; Nishimura et al., 2013b) and may facilitate functional recovery.

\section{References}

Barthélemy D, Leblond H, Provencher J, Rossignol S (2006) Nonlocomotor and locomotor hindlimb responses evoked by electrical microstimulation of the lumbar cord in spinalized cats. J Neurophysiol 96:3273-3292. CrossRef Medline

Barthélemy D, Leblond H, Rossignol S (2007) Characteristics and mechanisms of locomotion induced by intraspinal microstimulation and dorsal root stimulation in spinal cats. J Neurophysiol 97:1986-2000. CrossRef Medline

Bouyer LJ, Rossignol S (2003) Contribution of cutaneous inputs from the hindpaw to the control of locomotion: II. Spinal cats. J Neurophysiol 90:3640-3653. CrossRef Medline

Calancie B, Needham-Shropshire B, Jacobs P, Willer K, Zych G, Green BA (1994) Involuntary stepping after chronic spinal cord injury: evidence for a central rhythm generator for locomotion in man. Brain 117:11431159. CrossRef Medline

Carmena JM, Lebedev MA, Crist RE, O’Doherty JE, Santucci DM, Dimitrov DF, Patil PG, Henriquez CS, Nicolelis MA (2003) Learning to control a brain-machine interface for reaching and grasping by primates. PLoS Biol 1:E42. CrossRef Medline

Dimitrijevic MR, Gerasimenko Y, Pinter MM (1998) Evidence for a spinal central pattern generator in humans. Ann N Y Acad Sci 860:360-376. CrossRef Medline

Dorofeev IY, Avelev VD, Shcherbakova NA, Gerasimenko YP (2008) The role of cutaneous afferents in controlling locomotion evoked by epidural stimulation of the spinal cord in decerebrate cats. Neurosci Behav Physiol 38:695-701. CrossRef Medline

Drew T, Dubuc R, Rossignol S (1986) Discharge patterns of reticulospinal and other reticular neurons in chronic, unrestrained cats walking on a treadmill. J Neurophysiol 55:375-401. Medline
Ethier C, Oby ER, Bauman MJ, Miller LE (2012) Restoration of grasp following paralysis through brain-controlled stimulation of muscles. Nature 485:368-371. CrossRef Medline

Forssberg H, Grillner S (1973) The locomotion of the acute spinal cat injected with clonidine i.v. Brain Res 50:184-186. CrossRef Medline

Fujishiro T, Enomoto H, Ugawa Y, Takahashi S, Ueno S, Kitamura T (2000) Magnetic stimulation of the sacral roots for the treatment of stress incontinence: an investigational study and placebo controlled trial. J Neurol 164:1277-1279. CrossRef Medline

Gerasimenko YP, Avelev VD, Nikitin OA, Lavrov IA (2003) Initiation of locomotor activity in spinal cats by epidural stimulation of the spinal cord. Neurosci Behav Physiol 33:247-254. CrossRef Medline

Gerasimenko Y, Roy RR, Edgerton VR (2008) Epidural stimulation: comparison of the spinal circuits that generate and control locomotion in rats, cats and humans. Exp Neurol 209:417-425. CrossRef Medline

Gerasimenko Y, Gorodnichev R, Machueva E, Pivovarova E, Semyenov D, Savochin A, Roy RR, Edgerton VR (2010) Novel and direct access to the human locomotor spinal circuitry. J Neurosci 30:3700-3708. CrossRef Medline

Goldberger ME (1988) Partial and complete deafferentation of cat hindlimb: the contribution of behavioral substitution to recovery of motor function. Exp Brain Res 73:343-353. Medline

Grillner S, Zangger P (1979) On the central generation of locomotion in the low spinal cat. Exp Brain Res 34:241-261. Medline

Gurfinkel VS, Levik YS, Kazennikov OV, Selionov VA (1998) Locomotorlike movements evoked by leg muscle vibration in humans. Eur J Neurosci 10:1608-1612. CrossRef Medline

Harkema S, Gerasimenko Y, Hodes J, Burdick J, Angeli C, Chen Y, Ferreira C, Willhite A, Rejc E, Grossman RG, Edgerton VR (2011) Effect of epidural stimulation of the lumbosacral spinal cord on voluntary movement, standing, and assisted stepping after motor complete paraplegia: a case study. Lancet 377:1938-1947. CrossRef Medline

Huang HJ, Ferris DP (2004) Neural coupling between upper and lower limbs during recumbent stepping. J Appl Physiol 97:1299-1308. CrossRef Medline

Ichiyama RM, Gerasimenko YP, Zhong H, Roy RR, Edgerton VR (2005) Hindlimb stepping movements in complete spinal rats induced by epidural spinal cord stimulation. Neurosci Lett 383:339-344. CrossRef Medline

Jackson A, Mavoori J, Fetz EE (2006a) Long-term motor cortex plasticity induced by an electronic neural implant. Nature 444:56-60. CrossRef Medline

Jackson A, Moritz CT, Mavoori J, Lucas TH, Fetz EE (2006b) The Neurochip BCI: towards a neural prosthesis for upper limb function. IEEE Trans Neural Syst Rehabil Eng 14:187-190. CrossRef Medline

Kasten MR, Sunshine MD, Secrist ES, Horner PJ, Moritz CT (2013) Therapeutic intraspinal microstimulation improves forelimb function after cervical contusion injury. J Neural Eng 10:044001. CrossRef Medline

Kawashima N, Nozaki D, Abe MO, Nakazawa K (2008) Shaping appropriate locomotive motor output through interlimb neural pathway within spinal cord in humans. J Neurophysiol 99:2946-2955. CrossRef Medline

Kilgore KL, Hoyen HA, Bryden AM, Hart RL, Keith MW, Peckham PH (2008) An implanted upper-extremity neuroprosthesis using myoelectric control. J Hand Surg Am 33:539-550. CrossRef Medline

Lavrov I, Courtine G, Dy CJ, van den Brand R, Fong AJ, Gerasimenko Y, Zhong H, Roy RR, Edgerton VR (2008) Facilitation of stepping with epidural stimulation in spinal rats: role of sensory input. J Neurosci 28: 7774-7780. CrossRef Medline

Lucas TH, Fetz EE (2013) Myo-cortical crossed feedback reorganizes primate motor cortex output. J Neurosci 33:5261-5274. CrossRef Medline

Matsumoto H, Hanajima R, Terao Y, Ugawa Y (2013) Magnetic-motorroot stimulation. Clin Neurophysiol 124:1055-1067. CrossRef Medline

Matsuyama K, Drew T (2000) Vestibulospinal and reticulospinal neuronal activity during locomotion in the intact cat: II. Walking on an inclined plane. J Neurophysiol 84:2257-2276. Medline

Mavoori J, Jackson A, Diorio C, Fetz E (2005) An autonomous implantable computer for neural recording and stimulation in unrestrained primates. J Neurosci Methods 148:71-77. CrossRef Medline

Minassian K, Jilge B, Rattay F, Pinter MM, Binder H, Gerstenbrand F, Dimitrijevic MR (2004) Stepping-like movements in humans with complete spinal cord injury induced by epidural stimulation of the lumbar cord: electromyographic study of compound muscle action potentials. Spinal Cord 42:401-416. CrossRef Medline 
Moritz CT, Lucas TH, Perlmutter SI, Fetz EE (2007) Forelimb movements and muscle responses evoked by microstimulation of cervical spinal cord in sedated monkeys. J Neurophysiol 97:110-120. CrossRef Medline

Moritz CT, Perlmutter SI, Fetz EE (2008) Direct control of paralysed muscles by cortical neurons. Nature 456:639-642. CrossRef Medline

Mushahwar VK, Horch KW (2000a) Selective activation of muscle groups in the feline hindlimb through electrical microstimulation of the ventral lumbo-sacral spinal cord. IEEE Trans Rehabil Eng 8:11-21. CrossRef Medline

Mushahwar VK, Horch KW (2000b) Muscle recruitment through electrical stimulation of the lumbo-sacral spinal cord. IEEE Trans Rehabil Eng 8:22-29. CrossRef Medline

Mushahwar VK, Collins DF, Prochazka A (2000) Spinal cord microstimulation generates functional limb movements in chronically implanted cats. Exp Neurol 163:422-429. CrossRef Medline

Mussa-Ivaldi FA, Bizzi E (2000) Motor learning through the combination of primitives. Philos Trans R Soc Lond B Biol Sci 355:1755-1769. CrossRef Medline

Nishimura Y, Perlmutter SI, Fetz EE (2013a) Restoration of upper limb movement via artificial corticospinal and musculospinal connections in a monkey with spinal cord injury. Front Neural Circuits 7:57. CrossRef Medline

Nishimura Y, Perlmutter SI, Eaton RW, Fetz EE (2013b) Spike-timing dependent plasticity in primate corticospinal connections induced during free behavior. Neuron 80:1301-1309. CrossRef Medline

Norton JA, Mushawar VK (2010) Afferent inputs to mid-and lower-lumbar spinal segments are necessary for stepping in spinal cats. Ann N Y Acad Sci 1198:10-20. CrossRef Medline

Peckham PH, Keith MW, Kilgore KL, Grill JH, Wuolle KS, Thrope GB, Gorman P, Hobby J, Mulcahey MJ, Carroll S, Hentz VR, Wiegner A (2001) Efficacy of an implanted neuroprosthesis for restoring hand grasp in tetraplegia: a multicenter study. Arch Phys Med Rehabil 82:1380-1388. CrossRef Medline

Perreault MC, Drew T, Rossignol S (1993) Activity of medullary reticulospinal neurons during fictive locomotion. J Neurophysiol 69:2232-2247. Medline

Plautz EJ, Barbay S, Frost SB, Friel KM, Dancause N, Zoubina EV, Stowe AM, Quaney BM, Nudo RJ (2003) Post-infarct cortical plasticity and behavioral recovery using concurrent cortical stimulation and rehabilitative training: a feasibility study in primates. Neurol Res 25:801-810. CrossRef Medline

Pohlmeyer EA, Oby ER, Perreault EJ, Solla SA, Kilgore KL, Kirsch RF, Miller
LE (2009) Toward the restoration of hand use to a paralyzed monkey: brain-controlled functional electrical stimulation of forearm muscles. PLoS One 4:e5924. CrossRef Medline

Popovic DB, Popovic MB, Sinkjaer T, Stefanovic A, Schwirtlich L (2004) Therapy of paretic arm in hemiplegic subjects augmented with a neural prosthesis: a cross-over study. Can J Physiol Pharmacol 82:749-756. CrossRef Medline

Popovic MR, Curt A, Keller T, Dietz V (2001) Functional electrical stimulation for grasping and walking: indications and limitations. Spinal Cord 39:403-412. CrossRef Medline

Rossignol S, Dubuc R, Gossard JP (2006) Dynamic sensorimotor interactions in locomotion. Physiol Rev 86:89-154. CrossRef Medline

Saigal R, Renzi C, Mushahwar VK (2004) Intraspinal microstimulation generates functional movements after spinal-cord injury. IEEE Trans Neural Syst Rehabil Eng 12:430-440. CrossRef Medline

Selionov VA, Ivanenko YP, Solopova IA, Gurfinkel VS (2009) Tonic central and sensory stimuli facilitate involuntary air-stepping in humans. J Neurophysiol 101:2847-2858. CrossRef Medline

Serruya MD, Hatsopoulos NG, Paninski L, Fellows MR, Donoghue JP (2002) Instant neural control of a movement signal. Nature 416:141-142. CrossRef Medline

Thuret S, Moon LD, Gage FH (2006) Therapeutic interventions after spinal cord injury. Nat Rev Neurosci 7:628-643. CrossRef Medline

Ugawa Y, Rothwell JC, Day BL, Thompson PD, Marsden CD (1989) Magnetic stimulation over the spinal enlargements. J Neurol Neurosurg Psychiatry 52:1025-1032. CrossRef Medline

van den Brand R, Heutschi J, Barraud Q, DiGiovanna J, Bartholdi K, Huerlimann M, Friedli L, Vollenweider I, Moraud EM, Duis S, Dominici N, Micera S, Musienko P, Courtine G (2012) Restoring voluntary control of locomotion after paralyzing spinal cord injury. Science 336:1182-1185. CrossRef Medline

Wessberg J, Stambaugh CR, Kralik JD, Beck PD, Laubach M, Chapin JK, Kim J, Biggs SJ, Srinivasan MA, Nicolelis MA (2000) Real-time prediction of hand trajectory by ensembles of cortical neurons in primates. Nature 408:361-365. CrossRef Medline

Zanos S, Richardson AG, Shupe L, Miles FP, Fetz EE (2011) The Neurochip-2: an autonomous head-fixed computer for recording and stimulating in freely behaving monkeys. IEEE Trans Neural Syst Rehabil Eng 19:427-435. CrossRef Medline

Zehr EP, Komiyama T, Stein RB (1998) Cutaneous reflexes during human gait: electromyographic and kinematic responses to electrical stimulation. J Physiol 77:3311-3325. Medline 